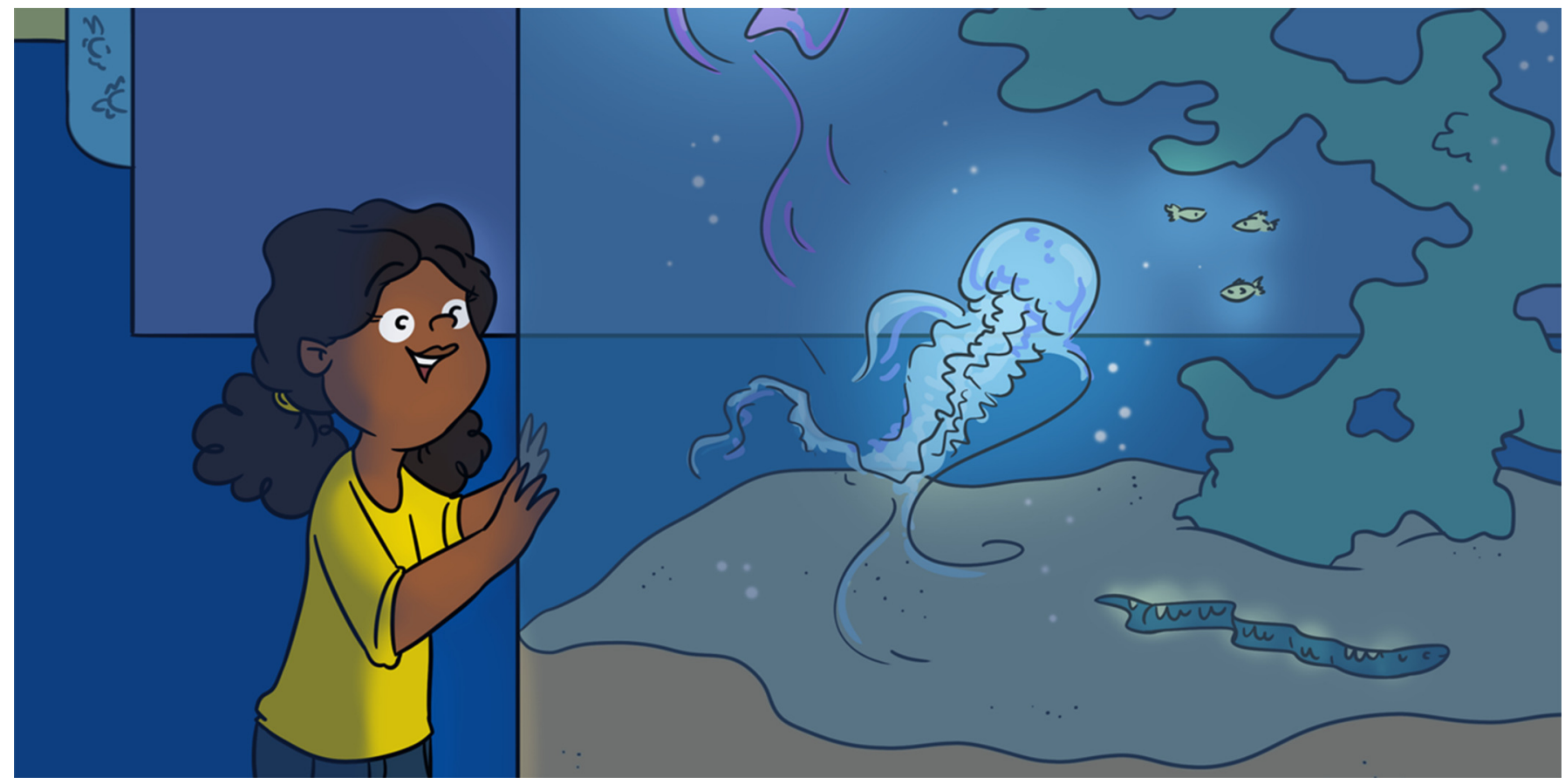

\title{
THE DARK OCEAN IS FULL OF LIGHTS
}

\section{Séverine Martini ${ }^{1 *}$ and Warren R. Francis ${ }^{2}$}

${ }^{1}$ UMR7093 Laboratoire d'Océanographie de Villefranche, Villefranche-sur-Mer, France

${ }^{2}$ Department of Biology, University of Southern Denmark, Odense, Denmark

YOUNG REVIEWERS:

JOHN

FISKE

ELEMENTARY SCHOOL

AGES: $12-14$

\section{BIOLUMINESCENCE}

The emission of light by living organisms.
Imagine that your body could emit light whenever you needed it. You would never be afraid in the dark or at night, because you could light up the world around you. You could shoot a flashing cloud under your bed so that monsters in the darkness would be blinded, while you escape. Many animals in the ocean can actually do that; this superpower is called bioluminescence! In the open sea, about three quarters of all animals are bioluminescent, and these animals can live anywhere from the surface down to 4,000 meters deep. This light emission is an efficient way to communicate with mates, attract prey, or escape predators in the darkness of the oceans.

\section{INTRODUCTION}

Do you know that most marine animals have a superpower that we do not have? It is called bioluminescence, from the words "bios," meaning life in Greek, and "lumen," meaning light in Latin. Bioluminescence is the ability of some living organisms to emit their own light. The word bioluminescence may sound similar to other 
Figure 1

Various ways that deep-sea animals use bioluminescence. (A) Luminous lure, (B) smoke screen, (C) counter-illumination,

(D) separable body part,

(E) "burglar alarm".
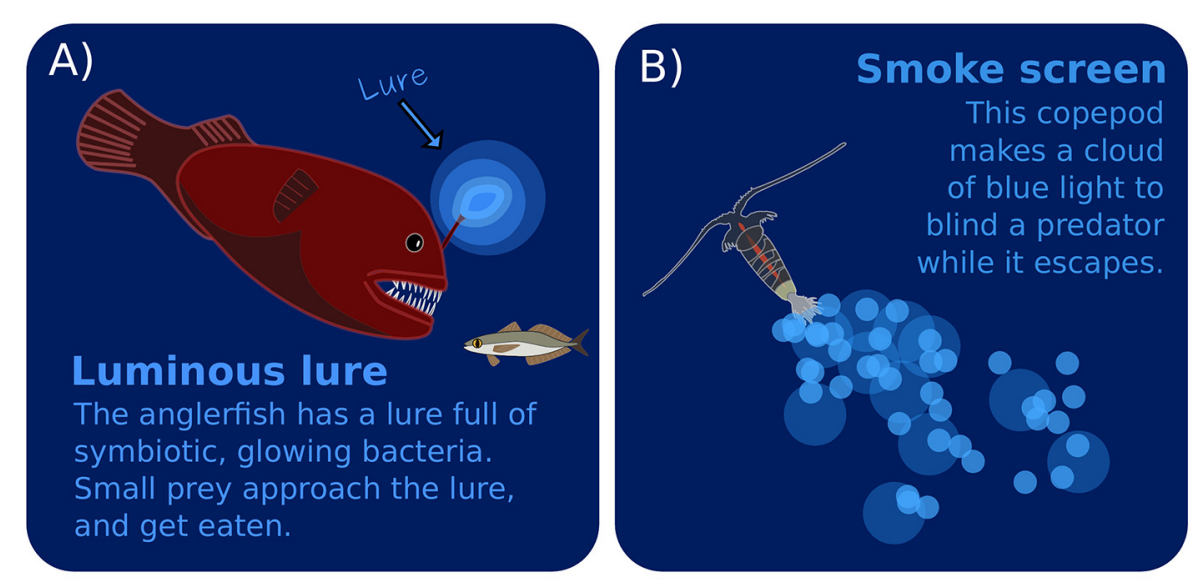

C)
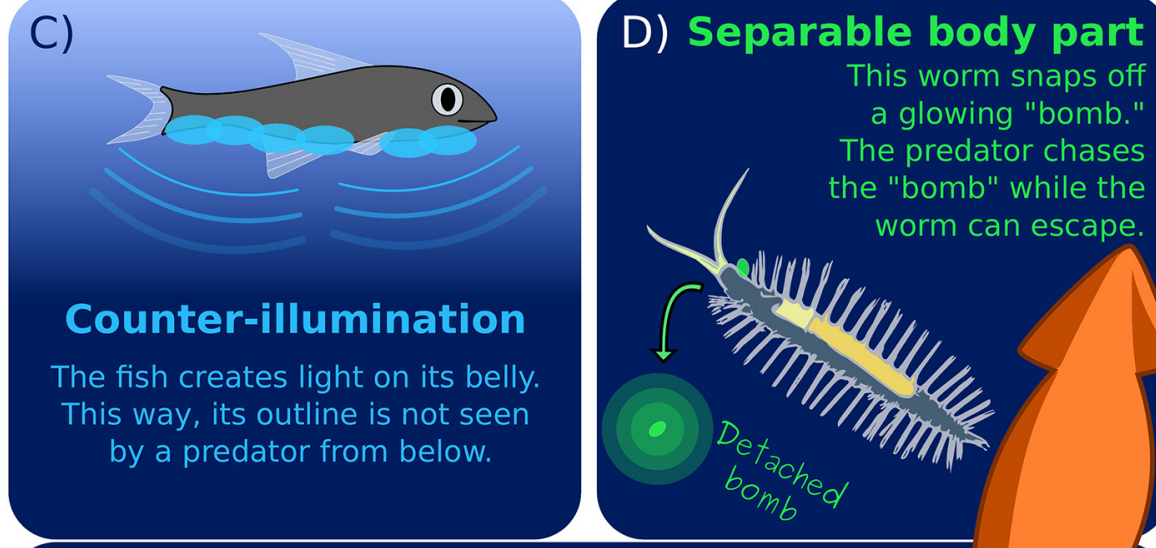

This worm snaps off a glowing "bomb."

The predator chases the "bomb" while the worm can escape.

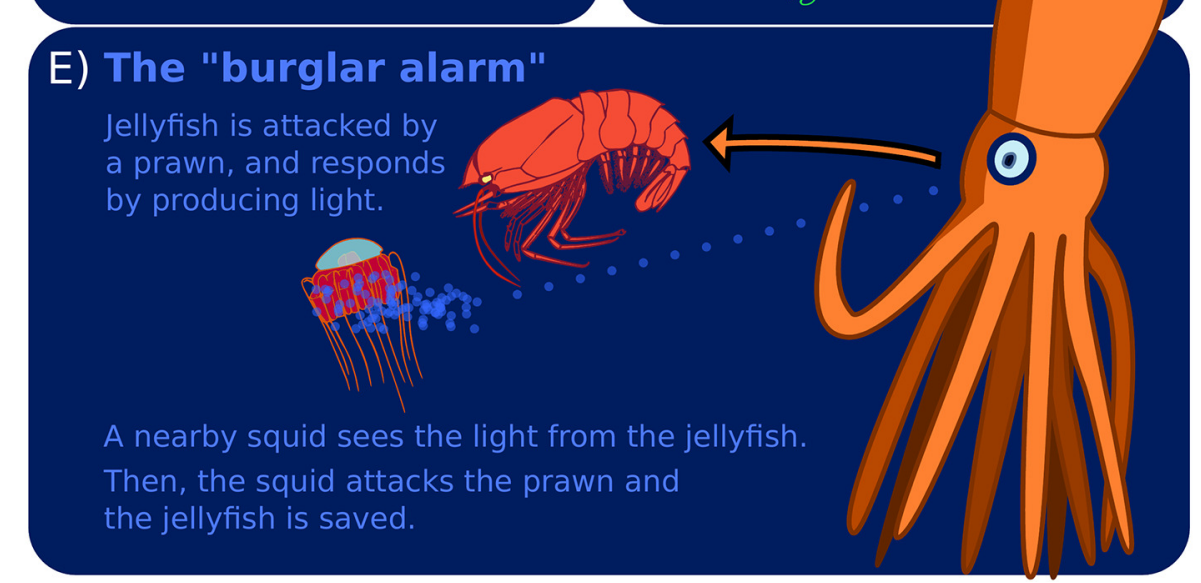

Figure 1

\section{LUCIFERIN}

A chemical acting with the luciferase during the bioluminescence chemical reaction.

\section{LUCIFERASE}

An enzyme involved into the bioluminescence chemical reaction. words, like "phosphorescence" (think of glow-in-the-dark toys), or "fluorescence" (think of highlighter markers), but they are completely different phenomena [1]. The main difference is that bioluminescence does not require any source of external light, like the sun or a flashlight. Bioluminescence is actually a chemical reaction (more like a glow-stick). This reaction was described for the first time in 1887 by the French biologist Raphael Dubois. The bioluminescent reaction requires two chemicals, one called a luciferin (which gets used up like batteries) and the other called a luciferase enzyme. The two chemicals react together, with a bit of oxygen, to produce light. 


\section{WHY EMIT LIGHT?}

Why do animals put their energy into making light? One reason to emit light is that, in the ocean, the sunlight barely penetrates deeper than a few hundred meters. Below that, it is completely dark. During the night, even the ocean surface is dark, except for the faint glow from the moonlight, so light is a great way for animals to communicate. But who are they communicating with and who else is seeing these signals? For marine species, emitting light or looking for light in the darkness helps them to find partners or even something to eat. For example, the angler fish uses its glowing lure to attract small prey that will undoubtedly end up in its stomach (Figure 1A). Of course, since the prey do not want to be eaten, they can use bioluminescence too, but as a defense. Many different strategies can be used [2]. Shooting a cloud of luminescent mucus is a way to leave predators dazzled for a few seconds (Figure 1B). Indeed, imagine that you have been in a dark room for a few minutes. If someone comes in and points a flashlight at your eyes, you will be blinded for a few seconds and unable to see anything-just enough time for the potential prey to escape.

Some fish and squid use bioluminescence for counter-illumination (Figure 1C). Normally, if these animals swim at the surface during the day, their silhouette against the sun would be visible to predators swimming beneath them. However, some fish and squid can produce light from their bellies to disrupt the silhouette and hide them from would-be predators. Another strategy used by some squid and worms is to detach part of their body as a sacrificed luminous target (Figure 1D). A predator then chases the glowing detached part while the prey escapes, similar to the way some reptiles can detach their own tails to escape predators. Lastly, some animals use light to attract help if they are being chased, which is sometimes called their "burglar alarm" (Figure 1E). Animals that are slow or fragile can have trouble escaping a predator by themselves, so they use the light to call out to something bigger and meaner that might want to eat the organism harassing the fragile animal.

\section{DIVERSITY OF LUMINOUS MARINE ORGANISMS}

Bioluminescent organisms are uncommon on land, though perhaps you have seen bioluminescent fireflies in your garden or in the countryside. In the ocean, however, they are found everywhere. There is a wide diversity of luminescent animals: fish, squid, jellyfish, some corals, different kinds of marine worms, ctenophores (pronounced "TEEN-o-fours," comb-jellies), sea stars, and crustaceans (some shrimps, for example). Among even stranger luminous animals, pyrosomes are organisms that look like long, gelatinous tubes (Figure 2A). They emit unusual brilliant, sustained light and, more amazingly, they luminesce in response to external light stimulation (Figure 2B). 
Figure 2

Pyrosomes: interesting bioluminescent animals. Pyrosomes are free-floating tube-shaped animals. They can range from a few centimeters to few meters in length. (A) A pyrosome observed under white light, which is like the light from the sun, or a lightbulb (@MBARI). (B) A pyrosome glowing, using bioluminescence (with permission from S.H.D. Haddock, (C) biolum.eemb. ucsb.edu/).

\section{PELAGIC}

Relating to the open water of the ocean, as distinguished from the benthic regions of the ocean.

1 https://www nature.com/articles/ d41586-01806660-2

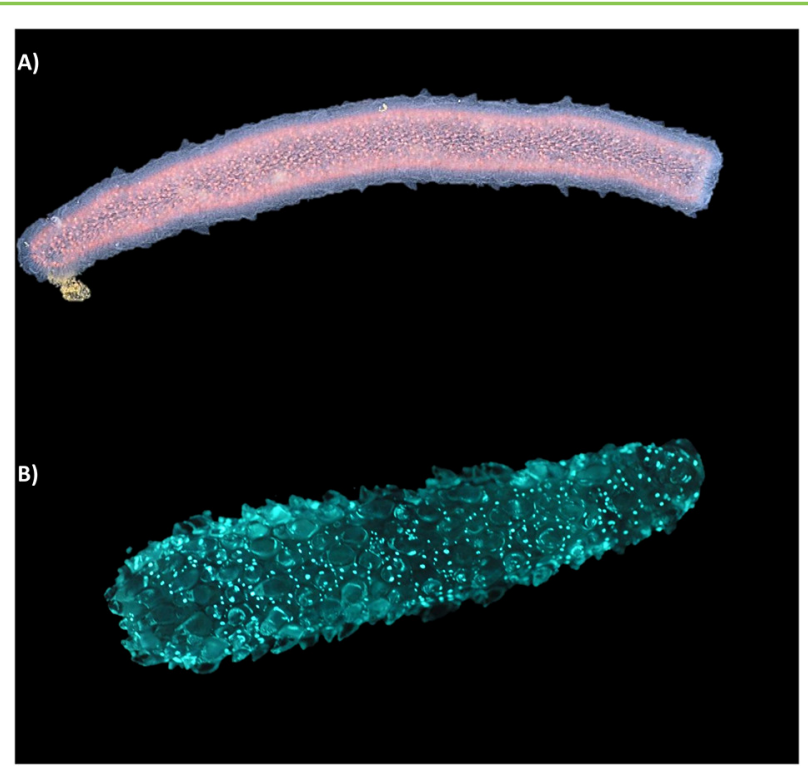

Figure 2

Most of the bioluminescence emitted by ocean animals looks blue or green, which are the colors (or wavelengths, in physics) that travel the furthest underwater. It has been observed that green light emitters are mainly found in shallow environments, while blue-turquoise light emitters are more often pelagic creatures, meaning they live in the open water [3]. However, the entire rainbow is used by bioluminescent organisms. Some jellyfish make light that looks purple. The marine worm named Tomopteris (pronounced "toe-MOP-ter-iss") emits yellow light in the form of bright glowing particles, a very uncommon color to emit in the deep sea. Scientists still do not understand how or why Tomopteris produces yellow light. Lastly, some fish, called dragonfish, even make red light. At this extreme wavelength, our eyes can barely see the red light, but our cameras can. The red light is probably used to search for prey, since most of the dragonfish's prey cannot see red light either.

The light emitted from bioluminescent animals is usually very short-lived, lasting from $<1 \mathrm{~s}$ to about $12 \mathrm{~s}$. The patterns of light are very diverse. Short flashes of bright light are emitted by copepods, and clouds of bioluminescence are produced from some ctenophores, siphonophores (relatives of jellyfish that form long chains), or chaetognaths (commonly called arrow worms). Another example is the sea cucumber, which does not look very pretty under normal light. However, in the dark, when some of them luminesce, we can see amazing, circular patterns of light over their entire bodies, like living fireworks ${ }^{1}$. The most incredible thing is that there are certainly many more bioluminescent patterns hidden in the deep ocean that nobody has ever seen. 
Figure 3

Bioluminescent animals can be found

throughout the ocean. Pelagic organisms are found in the water column, and around $76 \%$ of these animals are luminous. Benthic organisms are found close to the seafloor, and $30-40 \%$ of them are luminous.

\section{SYMBIOSIS}

Interaction or close living relationship between organisms from different species, usually with benefits to one or both organisms

\section{PHOTOPHORE}

Light-emitting organ present in some bioluminescent animals.

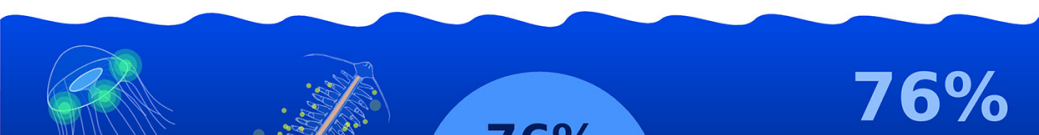

of pelagic organisms,

those that live in the open sea

not at the surface nor bottom, are thought to be luminous

The rest are known or suspected to be non-luminous

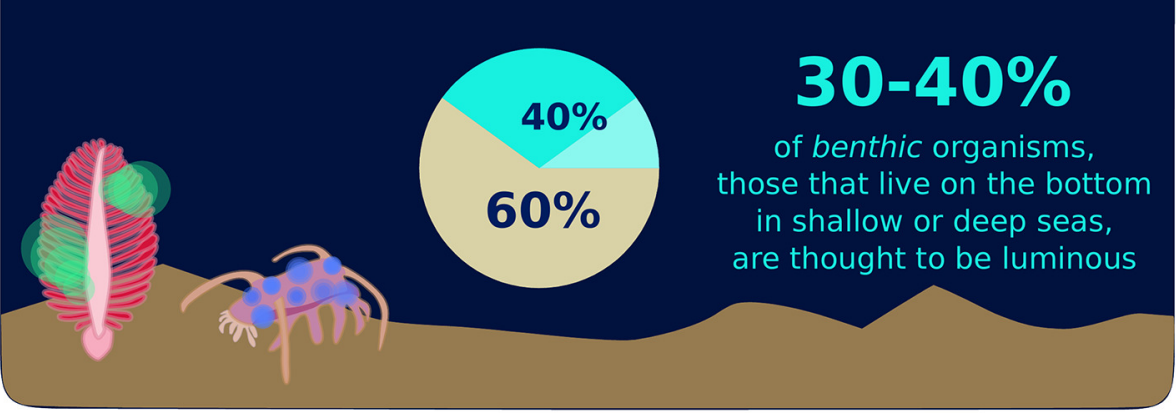

Figure 3

It is not just larger ocean animals that use light in these ways-some microscopic organisms can also be bioluminescent. Dinoflagellates (pronounced "dino-FLA-jel-lits") are often responsible for the bioluminescence observed at the sea surface. Their luminous traces can sometimes be seen at night behind sailing boats or if you disturb the water with your hand, at the beach. Even bacteria can be bioluminescent. Contrary to larger organisms, the light of bioluminescent bacteria is continuous. Bioluminescent bacteria can be found everywhere in the ocean: free in the water, attached to substances like plankton poop, or carcasses, or even in fish guts. These bacteria can also be found in a symbiotic relationship with other animals, living in specific light-organs of certain fish or squid. Like a team, in which each member of the team contributes something helpful, the larger animal provides nutrients (food) to the bacteria and, in return, uses the bacterial light to attract prey. A common example is the angler fish. This fish, which lives very deep down in the ocean, has a luminescent lure filled with luminous bacteria on its head, acting like a fishing rod. The anglerfish and bacteria are living together in a symbiotic relationship. However, bioluminescence through symbiosis is not common, and most organisms are self-luminescent, using specialized cells called photophores.

\section{HOW COMMON IS BIOLUMINESCENCE IN THE OCEAN?}

Researchers in submarines have reported that, during their descent into the deep ocean, a lot of the creatures disturbed by the vehicle were sparkling. However, it remains very difficult to observe these 


\section{BENTHIC}

Relating to the bottom of the sea or to the organisms that live there. glowing animals in their environments, several thousands of meters below the ocean surface. Recent analysis estimates that $76 \%$ of pelagic organisms (those that live in the open water) have the ability to emit light [4]. This means that most of the animals living between the surface and the deep ocean have this super-power. For benthic organisms (those that live close to the seafloor), the percentage is a little bit less-about 40\% of these animals are bioluminescent (Figure 3). Such variability is linked to the wavelengths of light that are most visible in these environments. Why is there such a different percentage of luminous pelagic animals compared with benthic animals? One main hypothesis is that bioluminescence is a way to communicate. To communicate with someone far away, light is very effective in the pelagic environment. On the contrary, for benthic animals, there are a lot of obstacles like rocks, cracks, and caves, or the water can be cloudy due to sediment stirred up by ocean currents. As a result, using light is probably not as effective for benthic organisms. Light might also be less necessary for bottom-dwellers, since there are many places to hide.

\section{CONCLUSION}

Bioluminescence is a fascinating superpower possessed by many of the marine creatures living in our oceans and frequently shown in movies or TV shows. While scientists have been aware of this ability and its mechanism for centuries, we are still far from understanding everything about bioluminescence. Indeed, researchers have not discovered all the reasons why animals or bacteria are bioluminescent. Also, the chemical reaction that creates bioluminescence, while understood for some animals, still remains secret for many other animals, such as some worms and many fish.

It is important for scientists to keep studying bioluminescence, because this fascinating ability of organisms remains undescribed or barely understood in many animals, while it has a major importance in the dark ocean.

\section{REFERENCES}

1. The Bioluminescence Web Page. Available online at: https://biolum.eemb. ucsb.edu/

2. Haddock, S. H., Moline, M. A., and Case, J. F. 2010. Bioluminescence in the sea. Annu. Rev. Mar. Sci. 2:443-93. doi: 10.1146/annurev-marine-120308-081028

3. Widder, E. A. 2010. Bioluminescence in the ocean: origins of biological, chemical, and ecological diversity. Science 328:704-8. doi: 10.1126/science. 1174269

4. Martini, S., and Haddock, S. H. 2017. Quantification of bioluminescence from the surface to the deep sea demonstrates its predominance as an ecological trait. Sci. Rep. 7:45750. doi: 10.1038/srep45750 
SUBMITTED: 04 December 2019; ACCEPTED: 20 April 2020;

PUBLISHED ONLINE: 28 May 2020.

EDITED BY: Sanae Chiba, Japan Agency for Marine-Earth Science and Technology (JAMSTEC), Japan

CITATION: Martini S and Francis WR (2020) The Dark Ocean Is Full of Lights. Front. Young Minds 8:69. doi: 10.3389/frym.2020.00069

CONFLICT OF INTEREST: The authors declare that the research was conducted in the absence of any commercial or financial relationships that could be construed as a potential conflict of interest.

COPYRIGHT @ 2020 Martini and Francis. This is an open-access article distributed under the terms of the Creative Commons Attribution License (CC BY). The use, distribution or reproduction in other forums is permitted, provided the original author(s) and the copyright owner(s) are credited and that the original publication in this journal is cited, in accordance with accepted academic practice. No use, distribution or reproduction is permitted which does not comply with these terms.

\section{YOUNG REVIEWERS}

\section{JOHN FISKE ELEMENTARY SCHOOL, AGES: 12-14}

We are group of students at smart young scientists participating in SMART science club. We are interested in different chemicals and substances. We are in seventh and eighth grade at John Fiske Elementary School. We are excited about the opportunity to work with scientists who study and write about bioluminescence. Our names are Joi, Brianna, Kingsley, Taliya, Hallel, Shamari, Shamar, and Camron.

\section{AUTHORS}

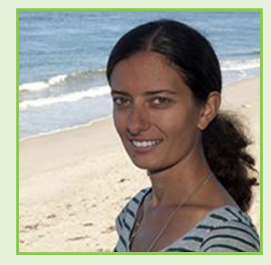

\section{SÉVERINE MARTINI}

I started working on bioluminescent bacteria during my Ph.D. in Marseille, France, at the Mediterranean Institute of Oceanography. My goal was to understand how these microorganisms adapt to the deep sea (high pressure and darkness). To pursue my research on larger marine species (jellies, invertebrates...), I worked for 2 years at the Monterey Bay Aquarium Research Institute (MBARI), in California, USA. MBARI is a world-leading laboratory specialized in deep-sea research and technologies. *martini.severine@agmail.com

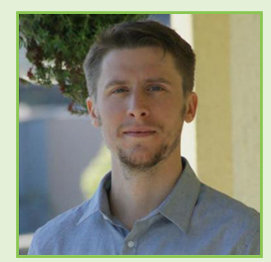

\section{WARREN R. FRANCIS}

My background is in biochemistry. I did my Ph.D. in California at the Monterey Bay Aquarium Research Institute, studying bioluminescence in a group of animals called ctenophores, the comb jellies. I have ongoing projects on a variety of luminous animals, polychaetes, squid, corals, and jellyfish, from both genetic and chemical perspectives. 